Received Date : 16-Mar-2015

Revised Date : 25-Sep-2015

Accepted Date : 22-Oct-2015

Article type : Original Manuscript

\title{
Patients' experiences with HMEs and attachments after total laryngectomy
}

Gian Franco Macri $\mathrm{MD}^{1}$, Hans Bogaardt $\mathrm{PhD}^{2}$, Claudio Parrilla $\mathrm{MD} \mathrm{PhD}^{3}$, prof. Antonio Minni $M D^{1}$, Lucia D'Alatri $M^{3}$, prof. Marco de Vincentiis $M D^{1}$, prof. Gaetano Paludetti $M^{3}$

1= Universita degli Studi La Sapienza di Roma, Rome, Italy

2= Speech Pathology, Faculty of Health Sciences, The University of Sydney, Sydney, Australia 3= Universita Cattolica del Sacro Cuore di Roma, Rome, Italy

\section{Correspondence:}

Hans Bogaardt, SLP PhD

Speech Pathology

Faculty of Health Sciences

The University of Sydney

75 East Street

Lidcombe NSW 2141

e-mail: hans.bogaardt@sydney.edu.au

Running title: Patients' experiences with the use of HMEs

Keywords: Laryngectomy, HME, adhesives, patients' experiences

This article has been accepted for publication and undergone full peer review but has not been through the copyediting, typesetting, pagination and proofreading process, which may lead to differences between this version and the Version of Record. Please cite this article as doi:

10.1111/coa. 12578

This article is protected by copyright. All rights reserved. 


\section{Abstract}

Objectives: The short-term and long-term beneficial effects of HME use by laryngectomees are well described in literature. In this study we document how laryngectomized patients, who previously did not use an HME, get accustomed to the use of HME and attachments.

Participants: Thirty patients, who were at least three months post-laryngectomy and previously did not use an HME, were followed for twelve weeks and were asked to complete questionnaires about their experiences with the HME and attachments.

Results: Results show that when patients start using an HME, they report some difficulties with breathing resistance during the first two weeks of use. However, after six weeks they have become accustomed to the breathing resistance and after 12 weeks over $96 \%$ reports that breathing was equal or less strenuous compared to breathing though an open stoma. Only a small proportion of patients experienced problems with increased coughing when starting HME use.

Conclusions: This study provides insight in the way laryngectomized patients are experiencing the use of HMEs in the first weeks. These outcomes can contribute to a better knowledge of HME use by healthcare providers and help them to manage patient expectations and improving support to patients in achieving compliant HME use.

\section{Introduction}

Total laryngectomy causes significant anatomical changes that interfere with normal physiological processes. Separating the alimentary and respiratory tracts with the creation of a permanent stoma at the base of the neck precludes normal pulmonary driven voice and speech, and lack of a nasal airflow leads to olfaction and pulmonary problems ${ }^{1}$. To reduce pulmonary symptoms, such as involuntary coughing and excessive phlegm production, patients normally use a heat and moisture exchanger (HME).

This article is protected by copyright. All rights reserved. 
The short-term and long-term beneficial effects of HME use by laryngectomees are well described in literature ${ }^{2,3,4}$. Zuur et al. concluded that in a cold environment, presence of an HME significantly increases both inspiratory and expiratory temperature and humidity values ${ }^{2}$. In a warm environment, however, presence of an HME has a cooling effect on the temperature while it still humidifies the inspired $a_{i r}{ }^{3}$. An earlier study by the same reseachers on endotracheal temperature and humidity and tidal volumes in laryngectomized patients significantly improved tracheal climate when an HME was used ${ }^{5}$. The study by Brook et al. showed compliant HME users tend to make less use of external humidifiers and vaporizers, and have better pulmonary status and lower health-care costs ${ }^{4}$. The HME devices in these mentioned studies can be attached to the tracheostoma in two different ways: peristomally (base plate) or intraluminally (laryngectomy tube or stoma button). For peristomal attachment the HMEs can be attached into a variety of available adhesives. Additionally, some patients may require the use of silicone glue to improve the seal of the adhesive to the $\mathrm{skin}^{6}$. For intraluminal attachment the HME device can be attached into a so-called laryngectomy tube or tracheostoma button ${ }^{7,8}$. Many laryngectomized patients require a laryngectomy tube to maintain stoma patency, especially in the early postsurgical days and during postoperative radiotherapy. Some patients experience permanent problems with stoma patency, requiring permanent use of a laryngectomy tube ${ }^{9}$. A recent study showed that $68 \%$ of long-term HME-users only use one type of attachment of which $76 \%$ used adhesives and $24 \%$ used a laryngectomy tube or stoma button ${ }^{4}$.

A recent Spanish study showed that $78 \%$ of laryngectomized patients that were prescribed HMEs used the HME consistently, while $22 \%$ abandoned its use despite the wellknown beneficial effects of HME use. The most common causes of desertion were adhesion problems due to mucus and skin irritation ${ }^{10}$. Van der Houwen et al. studied in detail (peri) stomal geometry data of a diverse population of laryngectomized patients in relation to adhesive use ${ }^{11}$. This study showed that there is a wide variation in (peri)-stomal anatomy, a wide variability in the use of stoma patches and a possible mismatch between the (peri) stomal anatomy and 
shape of the then available adhesive patches ${ }^{11}$. Therefore, their recommendation was that adhesives should be better designed to cover the wide variation of stoma anatomies, especially for patients with deeper stomas.

We hypothesized however that if compliance to HME use and attachments could be improved, one should investigate in detail how patients get accustomed to HMEs and attachments. Brook et al. describe that most patients learned about HME use from a speechlanguage pathologist (50\%) or a physician (42\%) and over $98 \%$ stated that they had received instruction on how to use an $\mathrm{HME}^{4}$. Next to this limited data, no studies have published data on the process of how patients get accustomed to HMEs and the problems they may encounter. In this study we document how laryngectomized patients, who previously did not use an HME, get accustomed to the use of HME and attachments and we will discuss clinical implications.

\section{Patients and Methods}

\section{Patients}

Patients were recruited at the Universita Cattolica del Sacro Cuore di Roma, Faculty of Medicine and Surgery 'Agostino Gemelli', and at the Universita degli Studi La Sapienza di Roma - Outpatient Clinic Umberto I. The study was approved by the relevant local Ethical Boards. All patients received written information and signed informed consent prior to inclusion. Included were adult laryngectomized patients with a stable pulmonary situation, who were longer than 3 months post treatment and did not use an HME. Excluded were patients with decreased level of consciousness and patients with reduced mobility of arms and/or hands, unable to insert and remove an HME independently.

This article is protected by copyright. All rights reserved. 


\section{Methods}

The study was carried out as a multi-center time-series design. The design of the study allowed the patients to act as their own control in order to reduce bias, allow for a control period, and eliminate possible climate effects.. After consenting to participate in this study, all patients used the Provox XtraHMEтм for twelve weeks in total. During these twelve weeks data collection took place after using the HME for two, six, and twelve weeks.

As there is to date no standardized questionnaire for the evaluation of the use of HMEs and attachments in laryngectomized patients, the questionnaire for this study had to developed by the researchers themselves. The first set of questions about the patients' experiences with the XtraHME were based on the article by Bien et al., where in a randomized controlled trial the effects of HME use was evaluated ${ }^{12}$ In this study a limited number of questions were asked about the patients' personal experiences with the HME and nine questions were selected to evaluate the personal experience of the patients participating in this study.

Hilgers et al. evaluated patients' experiences with a novel adhesive ${ }^{1}$ and four questions that were used in this study were selected from this publication. A fifth question was added and asked whether the patient had used an adhesive. For the patients' report of their pulmonary function, relevant questions used in the study by Herranz et al. ${ }^{14}$ were selected and eight questions were used in this study, totaling the number of questions in the questionnaire to 22 questions.

\section{HME and attachments}

During the 12 week intervention period, patients were provided with the two versions of the Provox® XtraHME ${ }^{\mathrm{TM}}$ : the XtraMoist ${ }^{\mathrm{TM}}$ HME Cassette, which can be worn day and night under normal physical effort, and the XtraFlow ${ }^{\mathrm{TM}} \mathrm{HME}$ Cassette with a lower breathing resistance intended for use during physical activities. The XtraFlow can also be used during the period of getting used to the increased breathing resistance of the HME. To attach the HME to the stoma, a variety of available Provox® adhesives (Provox® Optiderm ${ }^{\mathrm{TM}}$, Regular ${ }^{\mathrm{TM}}$, Flexiderm $^{\mathrm{TM}}$, 
XtraBase $^{\mathrm{TM}}$ and StabiliBase ${ }^{\mathrm{TM}}$ ) were available for the patients. For intraluminal attachment the LaryTube $^{\mathrm{TM}}$ or LaryButton ${ }^{\mathrm{TM}}$ was available.

All patients were provided with the possibility to use all different products in order to trial which would suit them best. To accommodate their choices and provide training on the different products, in the first two weeks of the intervention period they were also seen by the speech language pathologist.

\section{Statistical analyses}

Statistical analysis was performed using IBM SPSS 21.0 (SPSS Inc., Chicago, IL, USA). Dataanalysis took place on base of the treatment-per-protocol principle. All analyzed data is presented with mean, standard deviations and range of collected data. Reliability of the used questionnaire was determined by calculating Cronbach's alpha. All statistical tests are two-tailed and are evaluated with a $5 \%-l e v e l$ of significance.

\section{Results}

Patients were included between April 2012 and July 2013. Forty-one patients were initially included (38 males, 3 females): twenty-one at the Universita Cattolica del Sacro Cuore di Roma, Faculty of Medicine and Surgery 'Agostino Gemelli' and twenty at the Universita degli Studi La Sapienza di Roma- Outpatient Clinic Umberto I. Eleven patients dropped out of the study. One patient did not want to change his daily care, one patient did not want to travel anymore for this study, one patient had a recurrence of cancer in the neck and was excluded, one patient underwent a secondary puncture during the study and was excluded from the study, one patient withdrew due to skin irritation from the used adhesive, three patients found participation in this study too demanding and three patients deceased prior to the end of the study (no relation to this study). Subsequently the data of 30 patients (28 males, two females) were analyzed.

This article is protected by copyright. All rights reserved. 
Demographic data of the included patients is presented in Table 1. Average age at inclusion was 68.7 years old $(S D \pm 11.2$; range $40.8-90.3)$. Average time since laryngectomy was 51.7 months $(S D \pm 56.5$; range 4-223). Of these patients, 29 had undergone a neck dissection (26 bilateral, three unilateral). Four patients had undergone reconstructive surgery. Twenty-five patients had received radiotherapy (24 post-operative, one patient pre-operative) and 10 patients had received chemotherapy post-surgery. Ten patients had a voice prosthesis in situ at inclusion; seven patients used the Provox $2^{\mathrm{TM}}$-prosthesis and three patients used the Provox® Vega $^{\mathrm{TM}}$.

\section{General perception and experiences with HMEs}

The patients' experiences with the HME are presented in Table 2. Patients reported that (on average) it took them 6.8 days $\left(\mathrm{SD}_{ \pm} 6.1\right.$; range $\left.0-24\right)$ to get used to the XtraHMETM . All patients used the HME during the 12-week intervention period for more than 20 hours per day. Although a trend was visible in an increase of the number of hours of HME use over time $(20.2,21.1$ and 22.2 resp.), a repeated measurements ANOVA revealed no statistical difference in the hours of use of the HME at two weeks, six weeks and twelve weeks $(p=.240)$.

During the intervention period 23 patients (76.7\%) started with the use of a combination of the XtraMoist ${ }^{\mathrm{TM}}$ and the XtraFlow ${ }^{\mathrm{TM}}$, six patients $(20.0 \%)$ started with the XtraFlow ${ }^{\mathrm{TM}}$ and one patient (3.3\%) started with the XtraMoist ${ }^{\mathrm{TM}}$. After twelve weeks 19 patients $(65.5 \%)$ still used a combination of XtraFlow $^{\mathrm{TM}}$ and XtraMoist $^{\mathrm{TM}}$, seven patients $(24.1 \%)$ used the XtraFlow ${ }^{\mathrm{TM}}$ only and three patients used the XtraMoist ${ }^{\mathrm{TM}}$ only (10.3\%). During the intervention period there was no significant change in the incidence of the use of the type of HMEs or in the use of a combination of both $(p=.060)$.

At the start of HME use, 13 patients (43.3\%) reported that breathing had become more difficult during use of the HME. Seven patients (23.3\%) reported no changes and ten patients (33.3\%) found breathing through the HME less difficult. After twelve weeks only one patient

This article is protected by copyright. All rights reserved. 
(3.4\%) found it more difficult to breathe through the HME, seven patients $(24.1 \%)$ felt no difference and $21(72.4 \%)$ patients found breathing through the HME less difficult $(p=.002)$. The number of patients that sometimes would remove the HME when breathing became too difficult dropped from an initial $22(73.3 \%)$ to seven $(24.1 \%)$ after twelve weeks $(p=.001)$.

Noise coming from the HME when breathing was noticed by nine patients $(30.0 \%)$ at the start of HME use. After 12 weeks of HME use only three patients (10.3\%) reported noise when breathing $(p=.037)$.

A majority of patients rated their appearance with an HME consistently better or equal to their appearance with an open stoma with no significant changes over the 12 weeks $(p=.088)$. Throughout the twelve weeks, a large majority of patients consistently found breathing through an HME more hygienic than through an open stoma after two weeks of HME use $(p=.203)$. Twenty-five patients (83.3\%) rated the use of an HME to cover the stoma as 'pleasant' after two weeks with a non-significant increase to $96.6 \%$ after 12 weeks $(p=.165)$

Initially, six patients $(20.0 \%)$ had a little difficulty in placing the HME into the holder. At the end of the study, this number dropped to one patient $(3.4 \%)(p=.251)$. The main reason to replace an HME with a new one was when it was saturated with secretions. This reason was reported by 21 patients $(75.0 \%)$ at the start of the study and reduced to $65.5 \%$ at the end of the study, however this change was not significant $(p=.320)$.

\section{Patients' experiences with adhesives}

At the start of the intervention period three patients (10.0\%) used the Regular adhesive, nine patients $(30.0 \%)$ the Flexiderm ${ }^{\mathrm{TM}}$ adhesive, six patients $(20.0 \%)$ used the OptiDerm ${ }^{\mathrm{TM}}$ adhesive, one patient (3.3\%) used StabiliBase ${ }^{\mathrm{TM}}$ and ten patients $(33.3 \%)$ used other attachments, like the LaryButton ${ }^{\mathrm{TM}}$ (one patient) and the LaryTube ${ }^{\mathrm{TM}}$ (nine patients). All data regarding the use of adhesives are presented in Table 3 . None of the patients used a combination of adhesives. At the end of the study only six patients (20.7\%) still used the 
LaryTube $^{\mathrm{TM}}$ and none of the patients used a LaryButton ${ }^{\mathrm{TM}}$. The number of patients that uses an adhesive to attach the HME increased from $18(60.0 \%)$ at the start to 24 patients $(82.8 \%)$ after twelve weeks $(p=.014)$

At the start of the study two patients (11.8\%) reported that the adhesive did not stick well to the skin, while at the end of the study this was only the case in one patient $(4.2 \%)(p=.029)$.

Other questions regarding the use of adhesives, showed no statistical differences between two weeks, six weeks and 12 weeks. Initially, 35.5\% experienced problems with loosening of the adhesive when coughing, which reduced to $16.7 \%$ at the end of the study $(p=.166)$. At the start of the study (when 18 patients used an adhesive) the removal of the adhesive was not all painful or a little painful in 17 patients (94.4\%). After 12 weeks of HME use (when 24 patients used adhesives) 22 patients reported the removal of the adhesive was not at all painful or a little painful $(91.7 \% ; p=.331)$. Nine patients $(50.0 \%)$ reported no skin irritation due to the adhesive at the beginning of HME use. At the end of the study, 16 patients $(66.7 \%)$ did not report any skin irritation, seven $(29.2 \%)$ a little irritation and one patient $(4.2 \%)$ very much irritation $(p=.525)$.

\section{Patient experience with the effect of HMEs on pulmonary function}

After two, six and twelve weeks of XtraHME'M use, patients were asked to compare their present situation (i.e. with the $\mathrm{XtraHME}^{\mathrm{TM}}$ ) to their previous situation (i.e. without the XtraHME ${ }^{\mathrm{TM}}$ ). When asked whether patients had more or less tracheal dryness/irritation, after two weeks 18 patients $(60.0 \%)$ reported less irritation and 12 patients $(40.0 \%)$ reported no changes. After twelve weeks 24 patients (82.8\%) reported less irritation, four patients (13.8\%) reported no changes and one patient (3.4\%) reported more irritation $(p=.013)$ (Table 4$)$.

After two weeks of HME use, 19 patients reported less coughing (63.3\%) compared to the baseline period. In the following visits (after resp. six and 12 weeks of XtraHMETM use) the patients did not reported any further change in coughing $(p=.337)$. This was also seen for

This article is protected by copyright. All rights reserved. 
difficulty with coughing: $60.0 \%$ of the patients reported less difficulty after two weeks of $\mathrm{XtraHME}^{\mathrm{TM}}$ use and throughout the rest of the study there were no changes $(p=.336)$. Patients reported less mucus production and less frequent cleaning of the stoma after two weeks of XtraHMETM use.

Overall, when asked after 12 weeks of use, 17 patients (60.7\%) were 'very satisfied' with the use of the XtraHME'M, and 11 patients (39.3\%) were 'satisfied' with the use of the XtraHME $^{\text {TM }}$. None of the patients was dissatisfied with the XtraHMETM. Sixteen patients (55.2\%) responded that they would continue to use the XtraHME'M after the study has ended, 13 patients (44.8\%) responded that they would continue to use the XtraHME $^{\mathrm{TM}}$ after the study has ended but only could do so if the use of the $\mathrm{XtraHME}^{\mathrm{TM}}$ is reimbursed. None of the patients stated that they would not like to continue with the use of the XtraHME ${ }^{\mathrm{TM}}$.

As the direction of the questions in each of the three tables was different, it was not possible to calculate Cronbach's alpha as a measure of reliability over the total questionnaire. Analysis showed that the reliability using Cronbach's alpha of the questions presented in Tables 2,3 and 4 was $.565, .226$ and .791 respectively.

\section{Discussion}

Although the effects of the use of an HME has been described in the literature, describing both short-term ${ }^{2,14}$ and long-term ${ }^{4}$ positive effects on pulmonary function, so far no in-depth study has been conducted how patients get accustomed to these products. This is the first attempt to describe patients' experiences when starting with HMEs after laryngectomy.

Our data show that in the first two weeks patients will experience some discomfort of HME use like experiencing an increased breathing resistance (reported by $43 \%$ of our patients) and the need to remove the HME when breathing becomes too difficult (reported by $73 \%$ ). However, after six weeks of HME use, patients seem to be more accustomed to the HME and 
after 12 weeks only one patient $(3 \%)$ reported that breathing was more difficult with the HME. Interestingly, after 12 weeks of HME use over $70 \%$ of the patients reported that breathing with an HME is easier than breathing through an open stoma $(p=.002)$. An explanation might be that an HME (partially) restores the breathing resistance of the nose and restores normal lung function, allowing the patient to breathe more in accordance with normal physiology. HMEs have been shown to show significant improvements in inspiratory flow and volume values following use of the $\mathrm{HME}^{16}$, making it easier for the patient to breathe. However, our data suggest that a patient will need six weeks to experience this effect. The findings that over time breathing is experienced to be easier, is similar to the findings by Bien et al. ${ }^{12}$ and Brook et al. ${ }^{4}$ who both reported this long-term effect in compliant HME-users. Merol et al. found in their study that patients who use an HME experience better sleep as well ${ }^{16}$. In our study patients reported easier breathing through an HME after six weeks of HME use, which would be an explanation for the results found by Merol, as easier breathing during the night most likely will correlate to a better sleep.

There are some limitations to this study, as this study solely describes a cohort of patients without the use of control group. Based on the studies by Bien et al. ${ }^{12}$ and Dassonville et al. ${ }^{17}$ (with a maximum follow-up time of 12 weeks), one could argue that our inclusion criterion of minimum of three months after laryngectomy, would provide this study with a cohort of stable patients.

Another limitation is that no specific and validated questionnaire investigating the experience of laryngectomized patients with HMEs and attachments exists yet. Although the questions were developed by experienced speech language therapists and ENT surgeons with numerous years of experience with laryngectomized patients, the psychometric validity of the questions, as presented in this study, might be questioned. When interpreting the reliability analysis, one should take in account that Cronbach's alpha is highly influenced by the test

This article is protected by copyright. All rights reserved. 
length and dimensionality ${ }^{18}$. This would suggest that a very short number of questions (like Table 3 with four questions only) inevitably will result in a low alpha, making the result of the reliability analysis not lower than we expected for this number of questions per construct. However, the results of this study suggest the need for the development for a psychometric valid tool to evaluate this specific area of care for laryngectomized patients.

The data also show that, after two weeks of HME use, only a small proportion (10\%) of all patients report to cough more. After six weeks this number drops and after 12 weeks none of the patients report to cough more; almost $90 \%$ reports to cough less compared to the time when they did not use an HME. None of the patients reported that they coughed more. Our experience is that clinicians tend to tell patients that when they start using an HME, collected mucus in the airways might come loose and patients might experience a higher coughing frequency which will decrease in time. Our data suggest that this phenomenon exists, but only in a small proportion of patients. The vast majority of patients will experience a lower or equal coughing frequency from the beginning of HME use.

Based on our findings, it is recommendable that regular follow-ups by a speech language pathologist are scheduled in the first weeks after the start of HMEsas some patients report in the first weeks that they hear noise coming from the HME and a small proportion reports minor skin irritation. In a follow-up, the speech language pathologist should evaluate whether the patient needs another type of attachment (OptiDerm ${ }^{\mathrm{TM}}$ adhesive or LaryTube ${ }^{\mathrm{TM}}$ ) if skin irritation occurs. Also, in the follow-up the patients' technique of occluding the HME when speaking can be evaluated in order to reduce any concomitant noise coming from the HME when speaking. Also, our data shows that patients in the first two weeks will have difficulty with the attachment of the adhesive to the skin. After 12 weeks only one patient reported problems, showing that there is a learning curve for patients in the appliance of adhesives and from our clinical experience, support by a speech language pathologist could help the patient in learning how to attach an adhesive optimally.

This article is protected by copyright. All rights reserved. 
The data from this study provides more insight in the way patients are experiencing the use of HMEs in the first weeks after commencing to use these products. These outcomes can contribute to a better knowledge of HME use by healthcare providers and help to provide better information to patients on what they might expect when they start using HMEs. Based on our findings, it is recommendable that patients that start using HMEs have regular follow-ups in the first weeks, as in the first weeks the patient might experience some problems (especially with attachment of adhesive to the skin, unnecessary replacement of HME because due to nonremoval when coughing and in some cases minor problems with skin irritation).

\section{Conclusion}

When patients start using an HME, they may report in the first two weeks after start some difficulties with breathing resistance. However, after six weeks patients are generally accustomed to the breathing resistance and over $96 \%$ reports after 12 weeks of HME use that breathing is equal or less strenuous compared to breathing though an open stoma. A small proportion of patients $(10 \%)$ experiences problems with more coughing when starting with an $\mathrm{HME}$; in the weeks following the start of HME use, the coughing frequency will be lower than it used to be. Although over $80 \%$ used an adhesive as attachment, in the first weeks of HME use, patients tend also to use an intraluminal attachment. In the first weeks patients can experience problems with attaching the adhesive to the skin, however after twelve weeks of use, over $95 \%$ will not have any problems. Only a small proportion of the patients (4\%) will experience skin irritation at any stage of adhesive use.

\section{Acknowledgments}

The authors acknowledge Atos Medical AB, Sweden for providing the devices used in this study.

This article is protected by copyright. All rights reserved. 


\section{Literature}

1. Hilgers F.J., Dirven R., Wouters Y., Jacobi I., Marres H.A., van den Brekel, M.W. (2012) A multicenter, prospective, clinical trial evaluating a novel adhesive baseplate (Provox StabiliBase) for peristomal attachment of postlaryngectomy pulmonary and voice rehabilitation devices. Laryngoscope. 11, 2447-2453.

2. Zuur J.K., Muller S.H., Vincent A., Sinaasappel M., de Jongh F.H., Hilgers F.J. (2009) The influence of a heat and moisture exchanger on tracheal climate in a cold environment. Med Eng Phys. 7, 852-857.

3. Scheenstra R.J., Muller S.H., Hilgers F.J. (2011) Endotracheal temperature and humidity in laryngectomized patients in a warm and dry environment and the effect of a heat and moisture exchanger. Head Neck. 9, 1285-1293.

4. Brook I., Bogaardt H., van As-Brooks C. (2013) Long-term use of heat and moisture exchangers among laryngectomees: medical, social, and psychological patterns. Ann Otol Rhinol Laryngol. 6, 358-363.

5. Scheenstra R.J., Muller S.H., Vincent A., Sinaasappel M., Hilgers F.J. (2010) Influence of breathing resistance of heat and moisture exchangers on tracheal climate and breathing pattern in laryngectomized individuals. Head Neck. 8, 1069-1078.

6. Hilgers F.J., Ackerstaff A.H., Balm A.J., Gregor R.T. (1996) A new heat and moisture exchanger with speech valve (Provox stomafilter). Clin Otolaryngol Allied Sci. 5, 414-418.

7. Barton D., DeSanto L., Pearson B.W., Keith R. (1988) An endostomal tracheostomy tube for leakproof retention of the Blom-Singer stomal valve. Otolaryngol Head Neck Surg. 1, 38-41.

8. Hilgers F.J., Ackerstaff A.H. (2006) Development and evaluation of a novel tracheostoma button and fixation system (Provox LaryButton and LaryClip adhesive) to facilitate hands-free tracheoesophageal speech. Acta Otolaryngol. 11, 1218-1224.

This article is protected by copyright. All rights reserved. 
9. Ward E.C., Acton L.M., Morton A-L. (2007) Chapter 11. Stoma Care and Appliances. In: Ward EC, van As-Brooks CJ, editors. Head and Neck Cancer: Treatment, Rehabilitation, and Outcomes.San Diego: Plural Publishing. 289-311.

10. Pedemonte-Sarrias G., Villatoro-Sologaistoa J.C., Ale-Inostroza P., López-Vilas M., LeónVintró X., Quer-Agustí M. (2013) Chronic adherence to heat and moisture exchanger use in laryngectomized patients. Acta Otorrinolaringol Esp. 4, 247-252.

11. van der Houwen E.B., van Kalkeren T.A., Post W.J., Hilgers F.J., van der Laan B.F., Verkerke G.J. (2011) Does the patch fit the stoma? A study on peristoma geometry and patch use in laryngectomized patients. Clin Otolaryngol. 3, 235-241.

12. Bień S., Okła S., van As-Brooks C.J., Ackerstaff A.H. (2010) The effect of a Heat and Moisture Exchanger (Provox HME) on pulmonary protection after total laryngectomy: a randomized controlled study. Eur Arch Otorhinolaryngol. 3, 429-435.

13. Herranz J., Espiño M.A., Morado C.O. (2013) Pulmonary rehabilitation after total laryngectomy: a randomized cross-over clinical trial comparing two different heat and moisture exchangers (HMEs). Eur Arch Otorhinolaryngol. 9, 2479-2484.

14. Zuur J.K., Muller S.H., de Jongh F.H., van Zandwijk N., Hilgers F.J. (2006) The physiological rationale of heat and moisture exchangers in post-laryngectomy pulmonary rehabilitation: a review. Eur Arch Otorhinolaryngol. 1, 1-8.

15. Ackerstaff A.H., Hilgers F.J., Aaronson N.K., Balm A.J., van Zandwijk N. (1993) Improvements in respiratory and psychosocial functioning following total laryngectomy by the use of a heat and moisture exchanger. Ann Otol Rhinol Laryngol. 11, 878-83.

16. Mérol J.C., Charpiot A., Langagne T., Hémar P., Ackerstaff A.H., Hilgers F.J. (2012) Randomized controlled trial on postoperative pulmonary humidification after total laryngectomy: external humidifier versus heat and moisture exchanger. Laryngoscope. 2, 275-81.

17. Dassonville O., Mérol J.C., Bozec A., Swierkosz F., Santini J., Chaïs A., Marcy P.Y., Giacchero P., Chamorey E., Poissonnet G. (2011) Randomised, multi-centre study of the

This article is protected by copyright. All rights reserved. 
usefulness of the heat and moisture exchanger (Provox HME®) in laryngectomized patients. Eur Arch Otorhinolaryngol. 11, 1647-1654.

18. Tavakol M \& Dennick R. (2011) Making sense of Cronbach's alpha. Int J Med Educ. 2, 5355.

Table 1. Patients' characteristics $(n=30)$

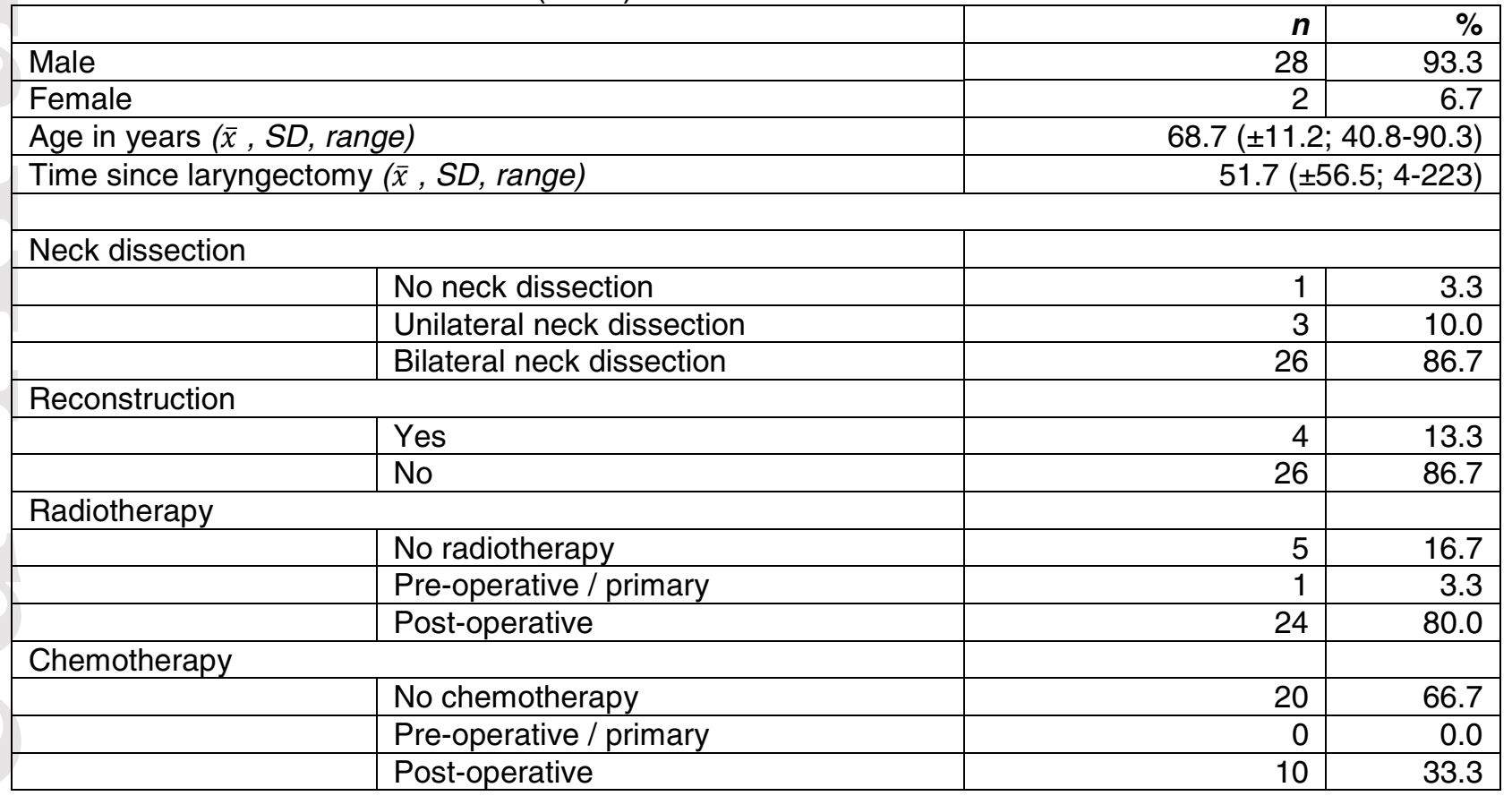

This article is protected by copyright. All rights reserved. 
Table 2. Patients' experiences with the XtraHME

\begin{tabular}{|c|c|c|c|c|c|c|c|}
\hline (2) & $2 n$ & & & & 12 & & $p$ \\
\hline $\begin{array}{l}\text { Do you like your appearance better or } \\
\text { worse? } \\
\qquad \begin{array}{l}\text { Better } \\
\text { Worse } \\
\text { Same }\end{array}\end{array}$ & $\begin{array}{r}18 \\
0 \\
12\end{array}$ & $\begin{array}{r}60.0 \\
0.0 \\
40.0\end{array}$ & 22 & $\begin{array}{r}78.6 \\
0.0 \\
21.4\end{array}$ & 13 & $\begin{array}{r}48 . \\
3 \\
6.9 \\
44 . \\
8\end{array}$ & $\begin{array}{r}.088 \\
1\end{array}$ \\
\hline $\begin{array}{l}\text { Pleasant or unpleasant to cover your stoma } \\
\text { by means of this HME? } \\
\text { unpleasant } \\
\text { the same } \\
\text { pleasant }\end{array}$ & $\begin{array}{r}4 \\
25\end{array}$ & $\begin{array}{r}3.3 \\
13.3 \\
83.3\end{array}$ & 28 & $\begin{array}{r}0.0 \\
6.7 \\
93.3\end{array}$ & 28 & $\begin{array}{r}.0 .0 \\
3.4 \\
96 . \\
6\end{array}$ & $\begin{array}{r}.165 \\
1\end{array}$ \\
\hline $\begin{array}{l}\text { Do you find breathing through the HME } \\
\text { more hygienic than an open stoma? } \\
\qquad \begin{array}{r}\text { not at all } \\
\text { a little } \\
\text { quite a bit } \\
\text { very much }\end{array}\end{array}$ & $\begin{array}{r}1 \\
5 \\
22\end{array}$ & $\begin{array}{r}6.7 \\
3.3 \\
16.7 \\
73.3\end{array}$ & 24 & $\begin{array}{r}0.0 \\
3.3 \\
16.7 \\
80.0\end{array}$ & 24 & $\begin{array}{r}0.0 \\
0.0 \\
17 . \\
2 \\
82 . \\
8\end{array}$ & $\begin{array}{r}.203 \\
2\end{array}$ \\
\hline $\begin{array}{l}\text { Do you hear noise coming from the HME } \\
\text { when you are breathing? } \\
\text { Yes } \\
\text { No } \\
\text { Don't know }\end{array}$ & $\begin{array}{r}9 \\
20 \\
1\end{array}$ & $\begin{array}{r}30.0 \\
66.7 \\
3.3\end{array}$ & 28 & $\begin{array}{r}6.7 \\
93.3 \\
0.0\end{array}$ & 25 & $\begin{array}{r}10 . \\
3 \\
86 . \\
2 \\
3.4\end{array}$ & $\begin{array}{r}.037 \\
1\end{array}$ \\
\hline
\end{tabular}

This article is protected by copyright. All rights reserved. 


\begin{tabular}{|c|c|c|c|c|c|c|c|}
\hline $\begin{array}{l}\text { Has your breathing with using the HME } \\
\text { been easier or more difficult? } \\
\text { more difficult } \\
\text { equal to without HME } \\
\text { less difficult }\end{array}$ & $\begin{array}{r}13 \\
7 \\
10\end{array}$ & $\begin{array}{l}43.3 \\
23.3 \\
33.3\end{array}$ & 19 & $\begin{array}{l}10.0 \\
26.7 \\
63.3\end{array}$ & 21 & $\begin{array}{r}3.4 \\
24 . \\
1 \\
72 . \\
4\end{array}$ & $\begin{array}{r}.002 \\
1\end{array}$ \\
\hline $\begin{array}{l}\text { Do you sometimes remove the HME when } \\
\text { breathing becomes too difficult? } \\
\qquad \text { Yes } \\
\text { No }\end{array}$ & 22 & $\begin{array}{l}73.3 \\
26.7\end{array}$ & 10 & $\begin{array}{l}33.3 \\
66.7\end{array}$ & $\begin{array}{r}7 \\
22\end{array}$ & $\begin{array}{r}24 . \\
1 \\
75 . \\
9\end{array}$ & $\begin{array}{r}.001 \\
1\end{array}$ \\
\hline $\begin{array}{l}\text { Do you have problems inserting the HME } \\
\text { into/onto the placeholder? } \\
\qquad \begin{array}{r}\text { not at all } \\
\text { a little } \\
\text { quite a bit } \\
\text { very much }\end{array}\end{array}$ & 24 & $\begin{array}{r}80.0 \\
20.0 \\
0.0 \\
0.0\end{array}$ & 26 & $\begin{array}{r}86.7 \\
10.0 \\
0.0 \\
3.3\end{array}$ & $\begin{array}{r}28 \\
1\end{array}$ & $\begin{array}{r}96 . \\
6 \\
3.4 \\
0.0 \\
0.0\end{array}$ & $\begin{array}{r}.251 \\
2\end{array}$ \\
\hline $\begin{array}{l}\text { Do you have problems removing the HME } \\
\text { from the placeholder? } \\
\qquad \begin{array}{r}\text { not at all } \\
\text { a little } \\
\text { quite a bit } \\
\text { very much }\end{array}\end{array}$ & 26 & $\begin{array}{r}86.7 \\
13.3 \\
0.0 \\
0.0\end{array}$ & 27 & $\begin{array}{r}90.0 \\
10.0 \\
0.0 \\
0.0\end{array}$ & $\begin{array}{r}27 \\
2 \\
0\end{array}$ & $\begin{array}{r}93 . \\
1 \\
6.9 \\
0.0 \\
0.0\end{array}$ & $\begin{array}{r}.659 \\
2\end{array}$ \\
\hline $\begin{array}{l}\text { What is the main reason for you to } \\
\text { replace an HME with a new one? } \\
\quad \text { routine replacement every } 24 \text { hours }\end{array}$ & & & & & & & $\begin{array}{r}.320 \\
1\end{array}$ \\
\hline
\end{tabular}

This article is protected by copyright. All rights reserved. 


\begin{tabular}{|r|r|r|r|r|r|r|r|}
\hline $\begin{array}{r}\text { When it is blocked with secretions } \\
\text { for increased breathing resistance }\end{array}$ & 5 & 17.9 & 10 & 34.5 & 8 & 27. \\
& 21 & 75.0 & 16 & 55.2 & 19 & 6 & 65. \\
& 2 & 7.1 & 3 & 10.3 & 2 & 5 & \\
\hline
\end{tabular}

${ }^{1}=$ related samples Friedman's two-way analysis of variance by ranks

${ }^{2}=$ rep. measurements ANOVA

Table 3. Patients' experiences with attachments

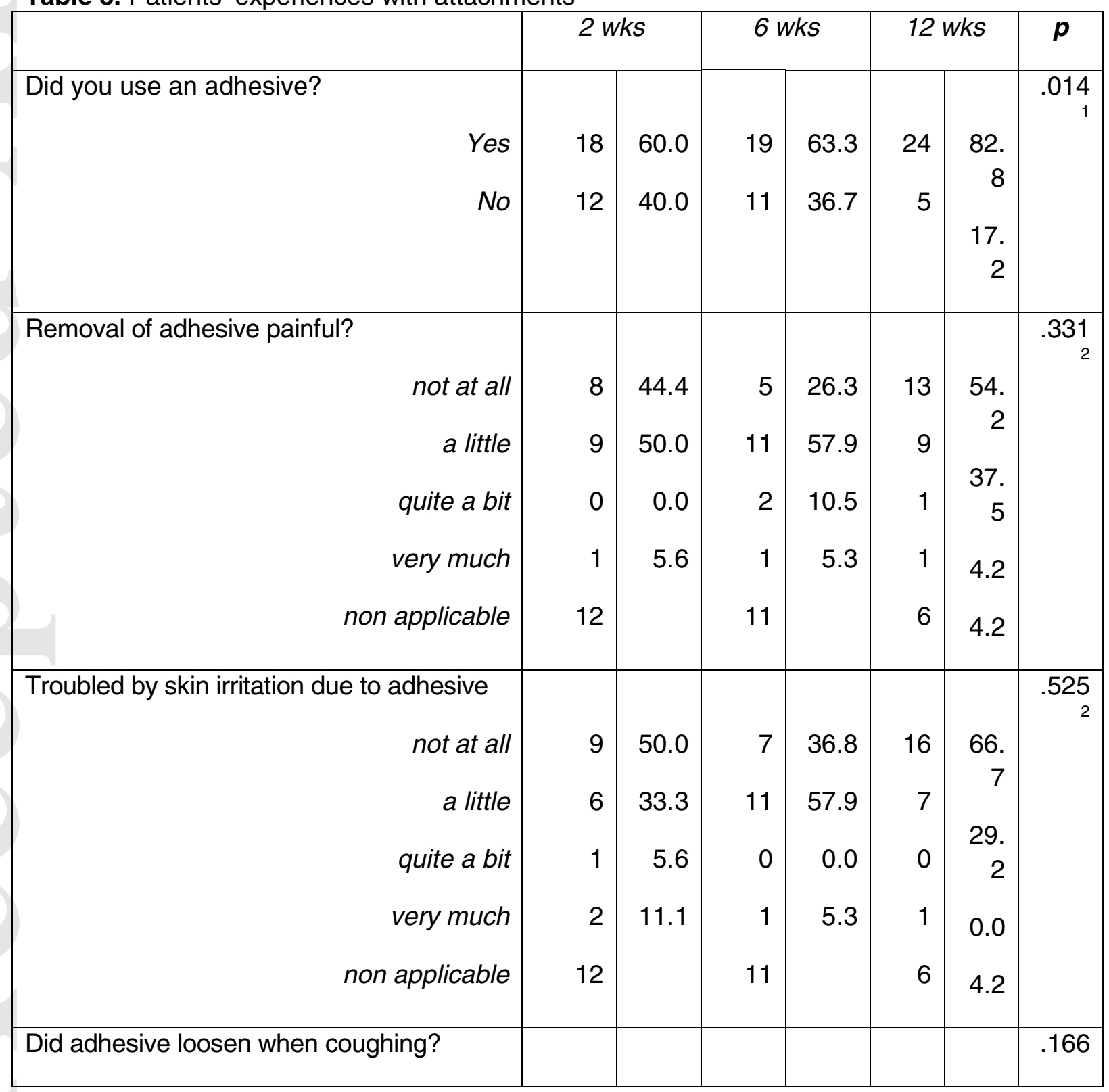

This article is protected by copyright. All rights reserved. 


\begin{tabular}{rr|r|r|r|r|r|r|r|}
\hline not at all & 11 & 64.7 & 10 & 52.6 & 20 & 83. & 2 \\
a little & 2 & 11.8 & 6 & 31.6 & 4 & 3 & \\
quite a bit & 3 & 17.6 & 3 & 15.8 & 0 & 7 & 16. \\
very much & 1 & 5.9 & 0 & 0.0 & 0 & 0.0 & \\
non applicable & 13 & & 11 & & 6 & 0.0 & \\
\hline nid adhesive stick well to the skin? at all & 2 & 11.8 & 2 & 10.5 & 1 & 4.2 & \\
a little & 2 & 11.8 & 4 & 21.1 & 0 & 0.0 & \\
quite a bit & 9 & 52.9 & 8 & 42.1 & 9 & 37. & \\
very much & 4 & 23.5 & 5 & 26.3 & 14 & 5 & \\
non applicable & 13 & & 11 & & 6 & 58. & \\
\hline
\end{tabular}

$1=$ related samples Friedman's two-way analysis of variance by ranks

${ }^{2}=$ rep. meas. ANOVA

Table 4. Patients' report on pulmonary function

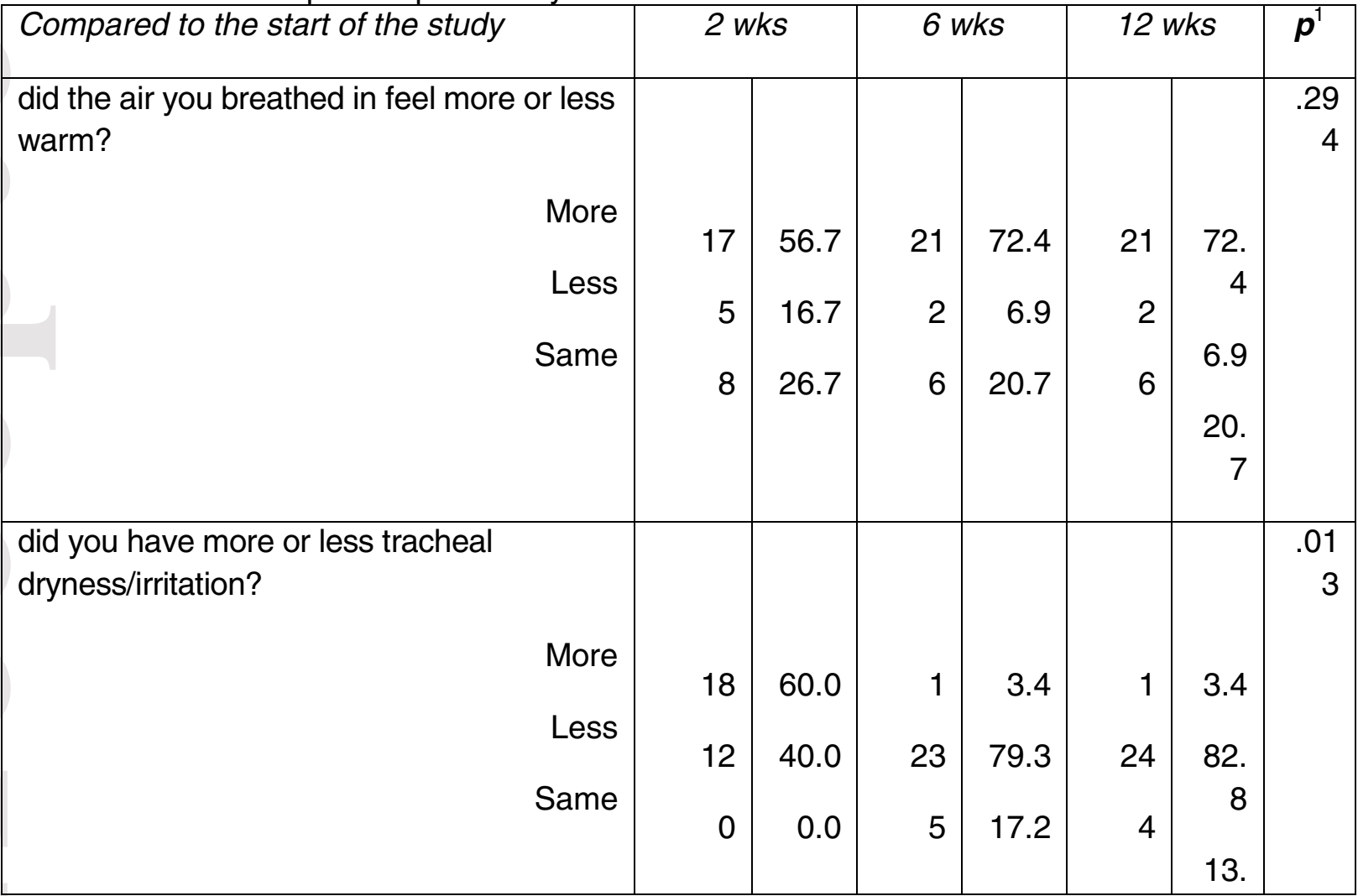

This article is protected by copyright. All rights reserved. 


\begin{tabular}{|c|c|c|c|c|c|c|c|}
\hline & & & & & & 8 & \\
\hline 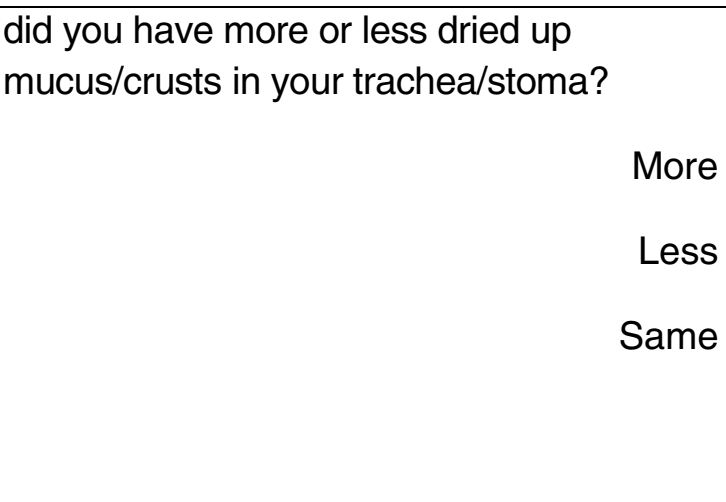 & $\begin{array}{r}20 \\
7\end{array}$ & $\begin{array}{l}10.0 \\
66.7 \\
23.3\end{array}$ & $\begin{array}{r}2 \\
27 \\
0\end{array}$ & $\begin{array}{r}6.9 \\
93.1 \\
0.0\end{array}$ & $\begin{array}{r}23 \\
4\end{array}$ & $\begin{array}{r}6.9 \\
79 . \\
3 \\
13 . \\
8\end{array}$ & $\begin{array}{r}.27 \\
3\end{array}$ \\
\hline $\begin{array}{l}\text { did you have more or less mucus } \\
\text { production? }\end{array}$ & $\begin{array}{r}1 \\
21 \\
8\end{array}$ & $\begin{array}{r}3.3 \\
70.0 \\
26.7\end{array}$ & $\begin{array}{r}2 \\
22 \\
5\end{array}$ & $\begin{array}{r}6.9 \\
75.9 \\
17.2\end{array}$ & $\begin{array}{r}23 \\
4\end{array}$ & $\begin{array}{r}6.9 \\
79 . \\
3 \\
13 . \\
8\end{array}$ & $\begin{array}{r}.36 \\
8\end{array}$ \\
\hline $\begin{array}{l}\text { did you have to clear your airways more or } \\
\text { less often by means of deliberate, forceful } \\
\text { coughing? } \\
\qquad \begin{array}{l}\text { More } \\
\text { Less } \\
\text { Same }\end{array}\end{array}$ & 19 & $\begin{array}{l}13.3 \\
63.3 \\
23.3\end{array}$ & $\begin{array}{r}1 \\
23 \\
5\end{array}$ & $\begin{array}{r}3.4 \\
79.3 \\
17.2\end{array}$ & $\begin{array}{r}1 \\
22 \\
6\end{array}$ & $\begin{array}{r}3.4 \\
75 . \\
9 \\
20 . \\
7\end{array}$ & $\begin{array}{r}.89 \\
5\end{array}$ \\
\hline did you cough more or less often? & $\begin{array}{r}3 \\
19\end{array}$ & $\begin{array}{l}10.0 \\
63.3 \\
26.7\end{array}$ & $\begin{array}{r}2 \\
25 \\
2\end{array}$ & $\begin{array}{r}6.7 \\
83.3 \\
6.7\end{array}$ & $\begin{array}{r}0 \\
26 \\
3\end{array}$ & $\begin{array}{r}0.0 \\
89 . \\
7 \\
10 . \\
3\end{array}$ & $\begin{array}{r}.33 \\
7\end{array}$ \\
\hline was coughing more or less difficult? & & & & & & & .33 \\
\hline
\end{tabular}

This article is protected by copyright. All rights reserved. 


\begin{tabular}{|c|c|c|c|c|c|c|c|}
\hline $\begin{array}{c}\text { More } \\
\text { Less } \\
\text { Same }\end{array}$ & $\begin{array}{r}2 \\
18 \\
10\end{array}$ & $\begin{array}{r}6.7 \\
60.0 \\
33.3\end{array}$ & $\begin{array}{r}1 \\
21 \\
7\end{array}$ & $\begin{array}{r}3.4 \\
72.4 \\
24.1\end{array}$ & $\begin{array}{r}1 \\
22 \\
6\end{array}$ & $\begin{array}{r}3.4 \\
75 . \\
9 \\
20 . \\
7\end{array}$ & 6 \\
\hline $\begin{array}{l}\text { did you have to clean the stoma more or } \\
\text { less often? } \\
\text { More } \\
\text { Less } \\
\text { Same }\end{array}$ & $\begin{array}{l}15 \\
10\end{array}$ & $\begin{array}{l}16.7 \\
50.0 \\
33.3\end{array}$ & $\begin{array}{r}2 \\
22 \\
5\end{array}$ & $\begin{array}{r}6.9 \\
75.9 \\
17.2\end{array}$ & $\begin{array}{r}2 \\
21 \\
6\end{array}$ & $\begin{array}{r}6.9 \\
72 . \\
4 \\
20 . \\
7\end{array}$ & $\begin{array}{r}.80 \\
7\end{array}$ \\
\hline
\end{tabular}

This article is protected by copyright. All rights reserved. 